D) Check for updates

Cite this as: $B M J 2021 ; 373: n 980$ http://dx.doi.org/10.1136/bmj.n980

Published: 19 April 2021

\section{Helen Salisbury: Will additional roles save general practice?}

This column (BMJ 2021;373:n946, doi:) has been updated to reflect that mental health workers have now been added to the list of roles in the Additional Roles Reimbursement Scheme. 